\title{
The friction properties of the HVOF sprayed coatings suitable for combustion engines, measured in compliance with ASTM G-99
}

\author{
Š. Houdková, M. Kašparová \& F. Zahálka \\ ŠKODA VÝZKUM s.r.o., Czech Republic
}

\begin{abstract}
The friction between a piston, piston rings and a cylinder is responsible for almost $55 \%$ of total power loss in engines. The decrease of friction in the piston area leads to a significant fuel saving and also to emission reduction. Application of a surface treatment, such as PEO, PVD, HVOF, plasma sprayed coatings, surface texturing, etc. on engine components is a way to reduce corrosion, friction, wear and weight of engines. In the paper, the potential of the application of HVOF sprayed coatings on the engine components is discussed with respect to their sliding friction properties. The technology of thermal spraying enables one to create the surface coating approximately $50 \mu \mathrm{m}$ thick, which provides functional surface protection of the coated parts. HVOF technology offers the possibility of creating the coatings of materials based on the principle of hardmetals with high wear resistance and favourable sliding properties. Such a combination predestinates HVOF sprayed coatings for sliding applications, such as pistons of combustion engines, pumps and other hydraulic devices. In this application area they are used on a regular basis. In practice, the producers and users of thermally sprayed coatings face the problem of the interaction of the coatings and their counterparts with the presence of other media, fuels, or, in the case of sliding wear more often, lubricants. The paper describes the methodology of measurement suitable for lubricated HVOF coatings using the pin-on-disc test according to ASTM G-99 and on the evaluation of the influence of lubricants on the friction properties, wear rate and mechanism of HVOF sprayed coatings. The pin-on-disc test according to ASTM G-99 was performed on the thermally sprayed $\mathrm{Cr}_{3} \mathrm{C}_{2}-25 \% \mathrm{NiCr}$ coating to determine and describe their sliding wear behaviour under different test conditions. The influence of various test parameters (load, wear track diameter, temperature, lubrication, counterpart
\end{abstract}


material) on the coefficient of friction, wear mechanism and wear rate was monitored.

Keywords: HVOF, coating, sliding friction, ASTM G-99, pin-on-disc.

\section{Introduction}

The pin-on-disc wear test is one of the most widespread tests for sliding wear behaviour and friction of material pairs. Its basic configuration can be seen in Fig. 1. The arrangement of the testing equipment can be both horizontal and vertical, while vertical configuration enables to remove the wear debris during the test. A radius tipped pin is pressed against a flat disc. The relative motion between them causes a circumferential wear path on the disc surface is generated. Either the pin or the disc can be moving.

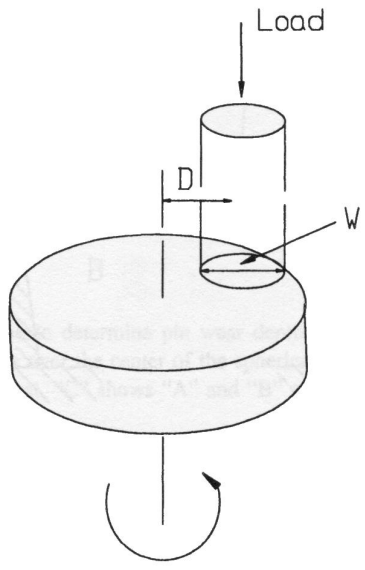

Figure 1: Diagram of the pin-on-disc test [1].

The test parameters that have been used vary. The ASTM standard for this test, ASTM G99, does not specify particular values for the parameters, but allows them to be selected by the user to provide the simulation of an application. The parameters can vary including size and shape of the pin, load, speed and material pairs. The test can be also performed in a controlled atmosphere and with lubrication [1]. The stress levels change during the test, as a result of the wear, and the relationship between wear and duration or amount of sliding is often non-linear. In order to make a material comparison, the ASTM standard recommends measuring the wear on both members after a fixed number of revolutions.

As a result of the pin-on-disc test, a mean value of coefficient of friction $(\mathrm{CoF}), \mathrm{CoF}$ evolution in dependence on the number of revolution or sliding distance, and the wear of tested material can be considered. The wear is evaluated by measurement of material volume loss that could be determined by measurement of weight or by measurement of wear track profile. 


\section{Experimental}

The thermally sprayed $\mathrm{Cr}_{3} \mathrm{C}_{2}-25 \% \mathrm{NiCr}$ material was used for sliding wear test measurements. The coating was sprayed by HP/HVOF JP-5000® (TAFA) spraying technology in the ŠKODA VÝZKUM s.r.o. in Plzeň, using the standard preparation procedure on the grit blasted substrate of carbon steel (ČSN 11 523) and the previously optimized spraying parameters [2].

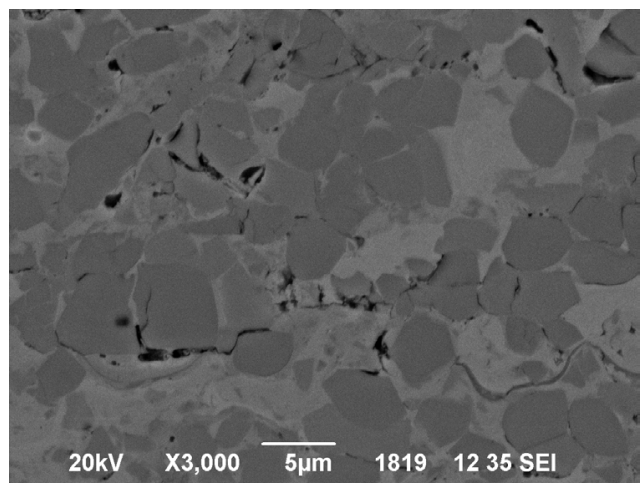

Figure 2: $\quad \mathrm{Cr}_{3} \mathrm{C}_{2}-\mathrm{NiCr}$ coating microstructure.

The microstructure of the HVOF sprayed $\mathrm{Cr}_{2} \mathrm{C}_{3}-25 \% \mathrm{NiCr}$ coating (Fig. 2) is slightly heterogeneous, with less than $1 \%$ of porosity. A characteristic feature of the $\mathrm{Cr}_{3} \mathrm{C}_{2}-\mathrm{NiCr}$ coatings is the presence of numerous carbide grains bonded to the metallic matrix $[3,4]$. Besides the $\mathrm{Cr}_{3} \mathrm{C}_{2}$ carbides and the $\mathrm{NiCr}$ matrix the coating also contains $\mathrm{Cr}_{2} \mathrm{O}_{3}$ oxide, originated during spraying as a result of the oxidation process, and probably also the $\mathrm{Cr}_{7} \mathrm{C}_{3}$ and the $\mathrm{Cr}_{23} \mathrm{C}_{6}$ carbides of the hardness lower than the primary $\mathrm{Cr}_{3} \mathrm{C}_{2}$, originated in the process of decarbonization during spraying similarly to the WC-Co coating [5]. The dissolution of carbides in the matrix leads to the increase in $\mathrm{C}$ and $\mathrm{Cr}$ concentration in the matrix compared to the powder composition. It enables the molten particles to solidify as the semi-amorphous or nanocrystalic $\mathrm{C}$ and $\mathrm{Cr}$ rich structure. The rapid solidification also contribute to the creation of other metal nanocrystalic phases with the grains size of cca $10 \mathrm{~nm}$ composed of $50 \% \mathrm{Ni}$ and $50 \% \mathrm{Cr}[6]$.

The basic mechanical properties of the tested $\mathrm{Cr}_{3} \mathrm{C}_{2}-25 \% \mathrm{NiCr}$ are summarized in Table 1. The value of indentation fracture toughness, stated in Table 1, was determined according to the Lawn-Fuller formula [7].

Table 1: $\quad \mathrm{Cr}_{3} \mathrm{C}_{2}-25 \% \mathrm{NiCr}$ coating mechanical properties.

\begin{tabular}{cccccc}
\hline Coating & $\begin{array}{c}\text { Thickness } \\
{[\mu \mathrm{m}]}\end{array}$ & $\begin{array}{c}\text { Density } \\
{[\mathrm{g} . \mathrm{cm}-3]}\end{array}$ & $\begin{array}{c}\text { Microhardness } \\
\text { HV0,3 }\end{array}$ & $\begin{array}{c}\text { Hardness } \\
\text { HR15N }\end{array}$ & $\begin{array}{c}\text { IFT (LF) } \\
{[\mathrm{MPa} . \mathrm{m}-1 / 2]}\end{array}$ \\
\hline $\mathrm{Cr}_{3} \mathrm{C}_{2}-\mathrm{NiCr}$ & $433 \pm 9$ & 6.646 & $1030 \pm 114$ & $91 \pm 0.8$ & $1.45 \pm 0.47$ \\
\hline
\end{tabular}


The coating sliding wear and friction properties were evaluated in the New Technology Center of University of West Bohemia in Plzeň (NTC ZČU), applying the pin-on-disc test according to ASTM G-99, using High Temperature Tribometer produced by CSM Instruments SA. The test was performed on the polished coating surface of the roughness $\mathrm{Ra} 0.16 \pm 0.04$. To study the influence of the test parameters on the sliding wear and friction coating properties the material of the pin, wear track diagonal, pin load and temperature varied from that usually used in NTC ZČU. The usually used parameters are: Pin: $\mathrm{Al}_{2} \mathrm{O}_{3}$ ball, $\varnothing 6 \mathrm{~mm}$, Pin load: $10 \mathrm{~N}$, Sliding speed: $0.1 \mathrm{~m} / \mathrm{s}$, Number of cycles: 50000 , Wear track diagonal: 2, 3.5 and $5 \mathrm{~mm}$, Temperature: $20^{\circ} \mathrm{C}$, Lubrication: dry. First, the measurement was performed by parental parameters. The influence of the wear track diagonal on the coating wear rate and the $\mathrm{CoF}$ dependence was evaluated. Then the material of the pin was altered by hardened steel, while for the other parameters the parental values were used. The influence of the pin load was evaluated by varying the pin load: 1, 2, 5 and $10 \mathrm{~N}$. The influence of the wear test temperature was evaluated by means of varying the temperature of the test: $20^{\circ} \mathrm{C}, 500^{\circ}$ and $700^{\circ} \mathrm{C}$. The influence of lubrication on a mean value and evolution of $\mathrm{CoF}$ were evaluated using 3 types of engine oils: mineral MOGUL 15W-40, semi-synthetic MOGUL 10W-40 and synthetic MOGUL 5W-40.

Besides the studied parameter, the number of cycles altered due to the specific condition of each set of measurement.

\section{Results and discussion}

Because the CoF measurement using parental parameters served as a basis for all measurements sets, there is a lot of experimental data concerning the value and evolution of $\mathrm{CoF}$ of $\mathrm{Cr}_{3} \mathrm{C}_{2}-\mathrm{NiCr}$ coating, measured at the same test parameters during a long period of time. The overview of experimental results can be seen in Table 2.

Table 2: $\quad \mathrm{CoF}$ values for the sliding pair $\mathrm{Cr}_{3} \mathrm{C}_{2}-25 \% \mathrm{NiCr}$ coating $-\mathrm{Al}_{2} \mathrm{O}_{3}$.

\begin{tabular}{ccccc}
\hline Experiment & $\begin{array}{c}2 \mathrm{~mm} \text { wear } \\
\text { track diagonal }\end{array}$ & $\begin{array}{c}3,5 \mathrm{~mm} \text { wear } \\
\text { track diagonal }\end{array}$ & $\begin{array}{c}5 \mathrm{~mm} \text { wear } \\
\text { track diagonal }\end{array}$ & Mean value \\
\hline 1 & $0.64 \pm 0.06$ & $0.66 \pm 0.09$ & $0.63 \pm 0.08$ & $0.64 \pm 0.01$ \\
2 & $0.58 \pm 0.06$ & $0.59 \pm 0.08$ & $0.60 \pm 0.07$ & $0.59 \pm 0.01$ \\
3 & $0.59 \pm 0.06$ & - & $0.57 \pm 0.08$ & $0.58 \pm 0.01$ \\
4 & $0.66 \pm 0.08$ & $0.68 \pm 0.09$ & $0.68 \pm 0.09$ & $0.67 \pm 0.01$ \\
Mean value & $0.61 \pm 0.03$ & $0.64 \pm 0.04$ & $0.62 \pm 0.04$ & $0.62 \pm 0.04$ \\
\hline
\end{tabular}

It can be stated, that the scatter of measured values is not high with the respect to fact, that the measured coatings sets were sprayed and measured during a long period of time (more than 5 years). The coating quality and also the accuracy of the tribometer were found reproducible. The evolution of the CoF curves in dependence on the number of cycles can be seen in Fig. 8. The $\mathrm{CoF}$ increased gradually to the stable value, which was reached at between $15-$ 
20 thousand cycles. The increase is connected with the high scatter of the $\mathrm{CoF}$ values. Similar $\mathrm{CoF}$ evolution was observed for all provided sets of experiments. The results can be found in the previous work [8-12] in more detail. The wear track diagonal did not influence the measured $\mathrm{CoF}$ in any set of measurement, so $\mathrm{CoF}$ could be considered independent of the wear track diagonal. Unfortunately, the same cannot be said about the wear rate. The wear loss of the hard wearresistant $\mathrm{Cr}_{3} \mathrm{C}_{2}-\mathrm{NiCr}$ coating is too small to be measured. The measurable wear would be achieved by the increase in either pin load or a number of cycles, which is beyond the measurement range of the used tribometer. For reproducible evaluation of sliding wear it is necessary to choose some other type of the tribometer or a wear test, such as block-on-ring or crossed-cylinder wear test [1]. The major wear mechanism of the HVOF hardmetal coating is connected with the gradual primary loss of the metal matrix from the areas between coatings' hard particles, followed by the weakening of their attachment and pulling them out of the coating surface. In the case of the $\mathrm{Cr}_{3} \mathrm{C}_{2}-\mathrm{NiCr}$ coating, due to its lower fracture toughness, a higher amount of carbides and also bigger wear debris are pulled-out and cause the fluctuation of CoF curve. The design of the CSM Tribometer does not allow the wear debris to naturally fall off; they are trapped in the wear track and serve as an abrasive medium. Then the mechanism of wear changes from sliding to abrasive wear $[2,13]$. In Figure $3 b$ the area of a considerable damage of the wear track bottom, the weakened carbides and the deformed matrix can be seen. In [14] the cermet coatings the wear mechanism is described as the contact between the pin and coatings' carbides, which are slightly protruding from the matrix due to grinding. Such a condition leads only to a very slight wear. In [14] the formation of the tribofilm consisting of the oxidized, plastically deformed matrix was recognized, and could also be expected.
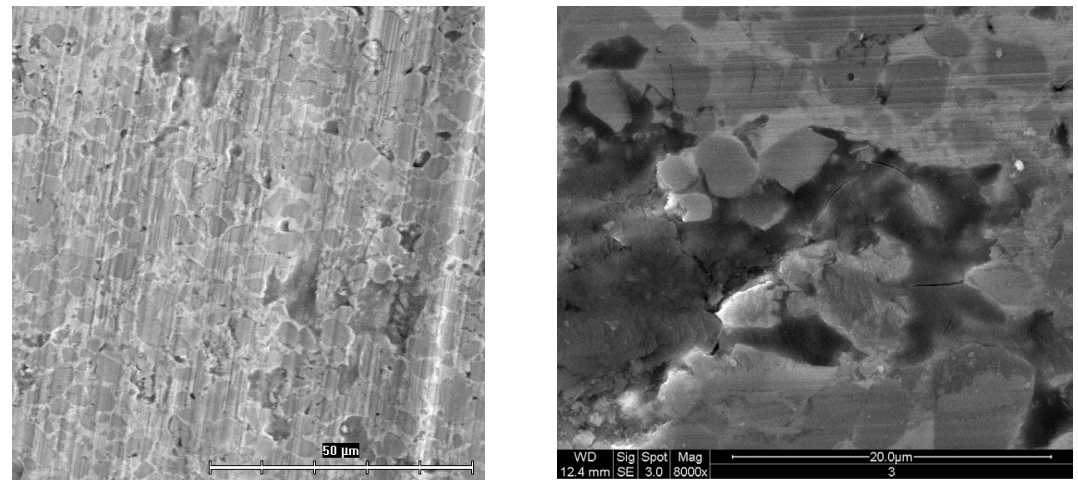

Figure 3: $\mathrm{OM}$ and $\mathrm{SEM}$ of wear track in the $\mathrm{Cr}_{3} \mathrm{C}_{2}-\mathrm{NiCr}$ coating.

The use of a hardened steel pin led to a significant increase in the middle CoF value (see Table 3) and to a change in the wear mechanism. The whole parts of the splats were pulled out in the case of the steel pin. Both effects could be caused by creation of micro-weld between pin material and NiCr matrix, or as it 
Table 3: $\quad$ CoF values for the sliding pair $\mathrm{Cr}_{3} \mathrm{C}_{2}-25 \% \mathrm{NiCr}$ coating - hardened steel.

\begin{tabular}{ccccc}
\hline Wear track diagonal $[\mathrm{mm}]$ & 2 & 3,5 & 5 & Mean value \\
\hline CoF & $0.75 \pm 0.06$ & $0.61 \pm 0.09$ & $0.78 \pm 0.08$ & $0.71 \pm 0.09$ \\
\hline
\end{tabular}

is mentioned in [15], the wear debris of the steel pin can serve as an abrasive medium that promotes the wear of Co binder in the coating and simultaneously cuts off the beneficial oxidic tribofilm.

The influence of the pin load on the $\mathrm{CoF}$ measured value of the sliding pair $\mathrm{Cr}_{3} \mathrm{C}_{2}-\mathrm{NiCr}-\mathrm{Al}_{2} \mathrm{O}_{3}$ can be seen from the data in Table 4 and from the graph in Fig 5. The stable value of $\mathrm{CoF}$ is decreasing, together with the used pin load. The running-in period is shorter for a lower pin load. Both effects can be caused by the increasing impact of the surface roughness on $\mathrm{CoF}$ with the decreasing load. The influence is described in [11] in more detail.

Table 4: $\quad \mathrm{CoF}$ values for the sliding pair $\mathrm{Cr}_{3} \mathrm{C}_{2}-25 \% \mathrm{NiCr}$ coating $-\mathrm{Al}_{2} \mathrm{O}_{3}-$ the influence of the pin load.

\begin{tabular}{ccccc}
\hline Pin load $\mathrm{L}[\mathrm{N}]$ & 10 & 5 & 2 & 1 \\
\hline CoF value & $0.53 \pm 0.01$ & $0.55 \pm 0.05$ & $0.64 \pm 0.04$ & $0.67 \pm 0.08$ \\
\hline
\end{tabular}

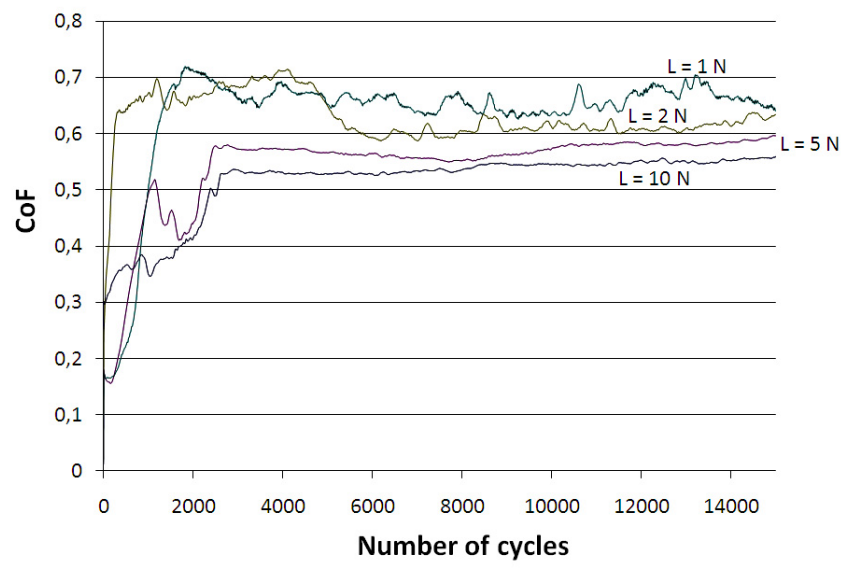

Figure. 5: The CoF evolution in dependence on the number of cycles - the influence of the pin load (smoothed curve).

The influence of a high temperature on the $\mathrm{CoF}$ values of the sliding pair $\mathrm{Cr}_{3} \mathrm{C}_{2}-\mathrm{NiCr}-\mathrm{Al}_{2} \mathrm{O}_{3}$ can be seen from the data in Table 5 and from the graph in Fig 6. The highest $\mathrm{CoF}$ was measured at room temperature. At $500^{\circ} \mathrm{C}$, the $\mathrm{CoF}$ was lower, its progression was steady, especially for $5 \mathrm{~mm}$ wear track diagonal. The lowest and most steady $\mathrm{CoF}$ was measured at the highest temperature, $700^{\circ} \mathrm{C}$. 
Table 5: $\quad \mathrm{CoF}$ values for a sliding pair $\mathrm{Cr}_{3} \mathrm{C}_{2}-25 \% \mathrm{NiCr}$ coating $-\mathrm{Al}_{2} \mathrm{O}_{3}-$ the influence of a high temperature.

\begin{tabular}{cccc}
\hline Temperature $\left[{ }^{\circ} \mathrm{C}\right]$ & 20 & 500 & 700 \\
\hline CoF value & $0.58 \pm 0.07$ & $0.47 \pm 0.01$ & $0.42 \pm 0.01$ \\
\hline
\end{tabular}

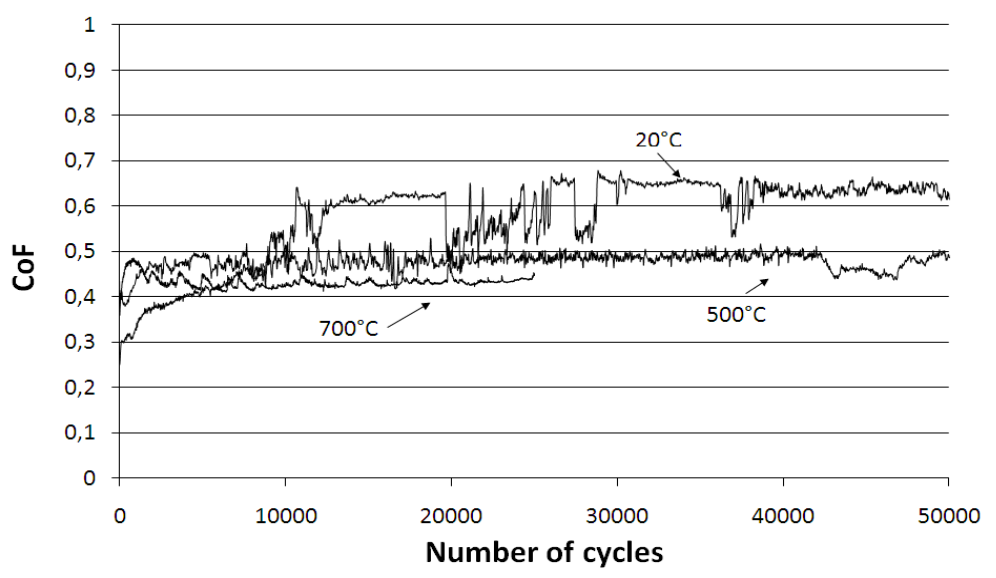

Figure. 6: The CoF evolution in dependence on the number of cycles - the influence of a temperature.
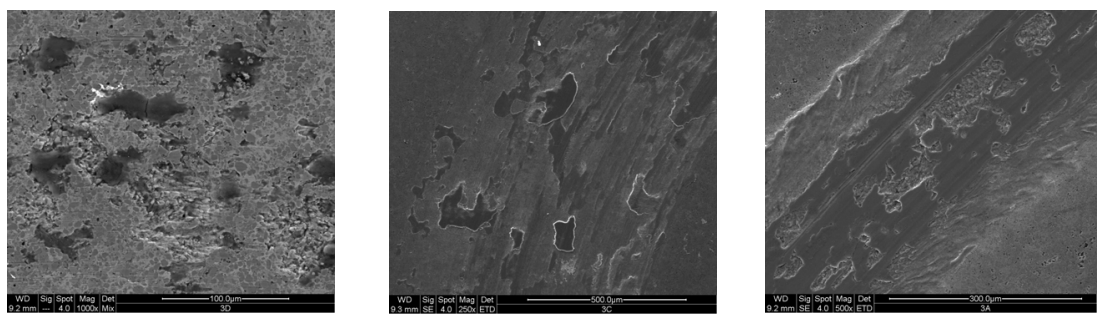

Figure 7: $\quad \mathrm{SEM}$ of the $\mathrm{Cr}_{3} \mathrm{C}_{2}-\mathrm{NiCr}$ wear track at a) $20{ }^{\circ} \mathrm{C}$, b) $500^{\circ} \mathrm{C}$ and c) $700^{\circ} \mathrm{C}$.

At elevated temperature, an oxide layer consisting of $\mathrm{Cr}_{2} \mathrm{O}_{3}$ and $\mathrm{NiCr}_{2} \mathrm{O}_{4}$ [16, 17] appears. The $\mathrm{Cr}_{2} \mathrm{O}_{3}$ layer adheres strongly to the coating's surface and is characterized by $\mathrm{CoF}$ values between $0.25-0.5$ [13], which is in a correlation with the CoF values measured in this study. According to $[15,16]$, the thickness and density of the oxide layer is different for $500^{\circ} \mathrm{C}$ and $700^{\circ} \mathrm{C}$. For $700^{\circ} \mathrm{C}$, it is thinner but denser, with better protective effect on the underlying surface. In [14] the existence of tribofilm on the $\mathrm{Cr}_{3} \mathrm{C}_{2}-\mathrm{NiCr}$ surface is described. In this study, its occurrence was proved by the EDX analyses of the oxygen amount in the wear track and on a free surface. The amount of oxygen absorbed in the wear track was higher compared to free surface for $\mathrm{Cr}_{3} \mathrm{C}_{2}-\mathrm{NiCr}$ coating, while for the other coatings it was the same. The influence of temperature on the friction 
properties of thermally sprayed hardmetal coatings is discussed in $[2,10]$ in more detail.

The influence of lubricants on the $\mathrm{CoF}$ values and evolution of the sliding pair $\mathrm{Cr}_{3} \mathrm{C}_{2}-\mathrm{NiCr}-\mathrm{Al}_{2} \mathrm{O}_{3}$ can be seen from the data in Table 6 and from the graph in Fig 8. The character of the lubricated friction is completely different. Besides the significant decrease in the CoF mean value the scatter also decreases, the curves are smooth and the measurements in the wear tracks with the different wear track radius are almost similar. Part of the CoF evolution curve characterized by the CoF increase due to the creation of the wear track is not present; on the contrary, the stable value is lower than the initial one and is reached during the first 1000 cycles. The part of the CoF curve is probably connected with the creation of a stable film of the lubricant [13].

Table 6: $\quad \mathrm{CoF}$ values for sliding pair $\mathrm{Cr}_{3} \mathrm{C}_{2}-25 \% \mathrm{NiCr}$ coating $-\mathrm{Al}_{2} \mathrm{O}_{3}-$ the influence of lubrication.

\begin{tabular}{cccc}
\hline Wear track diameter & $2 \mathrm{~mm}$ & $3 \mathrm{~mm}$ & $5 \mathrm{~mm}$ \\
\hline Dry friction & $0,658 \pm 0,085$ & $0,680 \pm 0,093$ & $0,677 \pm 0,087$ \\
MOGUL 5W-40 & $0,119 \pm 0,003$ & $0,123 \pm 0,002$ & $0,123 \pm 0,003$ \\
MOGUL 10W-40 & $0,120 \pm 0,003$ & $0,126 \pm 0,003$ & $0,126 \pm 0,003$ \\
MOGUL 15W-40 & $0,115 \pm 0,006$ & $0,121 \pm 0,003$ & $0,121 \pm 0,003$ \\
\hline
\end{tabular}

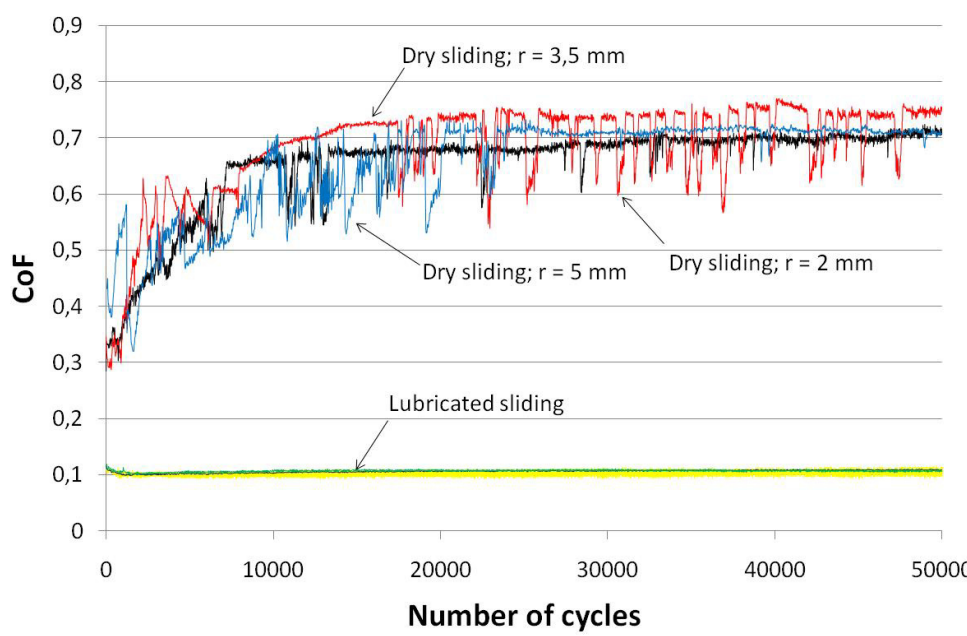

Figure 8: The CoF evolution in dependence on the number of cycles - the influence of lubrication.

The differences in values and character of $\mathrm{CoF}$ originated as a consequence of using different lubricants are very small, in terms of ASTM G-99 almost imperceptible. The lowest CoF was measured for MOGUL 15W-40, followed by MOGUL 5W-40 and MOGUL 10W-40. 
The wear track bottom (Fig. 9) of the coating lubricated with MOGUL 5W-40 shows significantly lower wear damage, without the signs of the carbides loss. Only random cracks in the carbides and in the boundaries between the carbides and the matrix appeared. Comparing the SEM micrographs it can be said that the lubrication decreases the wear of the coated surface and it can be presumed that the wear rate, expressed by means of material volume loss, will be lower in the case of lubricated sliding, too. More information about the influence of lubricants can be found in [7].

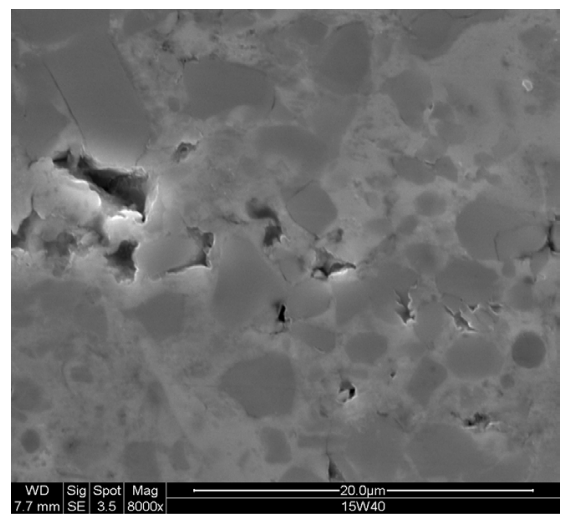

Figure 9: $\quad \mathrm{SEM}$ of the $\mathrm{Cr}_{3} \mathrm{C}_{2}-\mathrm{NiCr}$ wear track performed under lubricated conditions.

\section{Conclusion}

To fully understand the friction and wear behavior of the HVOF sprayed $\mathrm{Cr}_{3} \mathrm{C}_{2^{-}}$ $25 \% \mathrm{NiCr}$ coating, the study of the influence of various pin-on- disc test parameters was performed with respect to the $\mathrm{CoF}$ mean values, the $\mathrm{CoF}$ dependence on the number of cycles and the wear mechanism. The wear rate of the coating was not evaluated due to a very small volume loss of hard, wear resistant coating, which is not reproducibly measurable. It was found that the hardened steel pin in the sliding pair with the $\mathrm{Cr}_{3} \mathrm{C}_{2}-25 \% \mathrm{NiCr}$ coating causes higher $\mathrm{CoF}$ compared to the sliding pair $\mathrm{Cr}_{3} \mathrm{C}_{2}-25 \% \mathrm{NiCr}$ coatig- $\mathrm{Al}_{2} \mathrm{O}_{3}$. The higher the used pin load, the lower the $\mathrm{CoF}$ in the case of $\mathrm{Al}_{2} \mathrm{O}_{3}$ pin. The high temperature leads to the creation of an oxide tribofilm in the wear track, which has better sliding properties than the original $\mathrm{Cr}_{3} \mathrm{C}_{2}-25 \% \mathrm{NiCr}$ surface. The $\mathrm{CoF}$ decreases with the increasing test temperature. The presence of the lubricant decreases the CoF value more than 5 times, the wear mechanism is changing to be less pronounced. The wear track under the lubricated condition is almost undistinguishable from the untouched surface.

Another important test parameter affecting the friction and wear properties is a sliding speed. Its influence will be studied in the near future. 


\section{Acknowledgement}

The paper was written thanks to the financial support of the EUREKA E!4504 Project No. OE09001

\section{References}

[1] Bayer, R. G., Mechanical Wear Prediction and Prevention, Pub. Marcel Dekker, Inc, NY, USA (1994)

[2] Houdková, Š., Kašparová, M., Zahálka, F., Tribological behaviour of thermally sprayed coatings under high temperature, Proc. of Vrstvy a povlaky 2007, 29.-30.10.2007, Rožnov pod Radhoštěm, ISBN 978-80969310-4-0, p. 49 (in Czech)

[3] Berger, L.M., Structure, Properties and Potentials of $\mathrm{WC}-\mathrm{Co}, \mathrm{Cr}_{3} \mathrm{C}_{2}-\mathrm{NiCr}$ and TiC-Ni based Hardmetal Like Coatings, In Proceeding of the 9th National Thermal Spray Conference 1996, ASM International, Materials Park, OH, USA, 1996, ISBN: 0-87170-583-4

[4] Berger, L.-M., Hardmetals as Thermal Spray Coatings, Powder Metallurgy, 50 (2007) 3, pp. 205-214.

[5] Berger, L.-M., Chemistry of carbide-metal composites for preparation of HVOF sprayed coatings, Papers, Materials Week 2001, Int. Cong. On Adv. Mater., their Processes and Applications, 1.4. October 2001, München, [CD-ROM]. 2002. p. 10. (ISBN 3-88355-302-6)

[6] Zimmermann, S., Kreye, H., Chromium carbide Coatings produced with Various HVOF Spray Systems, In Proceeding of the 9th National Thermal Spray Conf., Cincinnati, ASM International, Materials Park, Ohio, USA (1996), pp.147-152

[7] Lawn, B.R., Fuller, E.R., J. Material Science, 10, (1975), pp. 2016-2024

[8] Houdková, Š., Zábranská, I., Zahálka, F., The influence of lubricants on friction properties of HVOF sprayed coatings, suitable for combustion engines, In. Proc. Of 18th International conference on Metallurgy and Materials METAL 2009, May 19-21, Hradec nad Moravicví, Czech Rep., (2009), ISBN 978-80-87294-10-9, pp.258-265

[9] Houdková, Š., Zahálka, F., Kašparová, M., The influence of thermally sprayed coatings microstructure on their mechanical and tribological characteristics, Material Science Forum 2008, Vols. 567-568 (2007), pp 229-232.

[10] Houdková, Š., Zahálka, F., Kašparová, M., Berger, L.-M., Tribological behaviour of thermally sprayed coatings at elevated temperatures, In. Proc. of International Thermal Spray Conference (2008) June 2-4, Maastricht, The Netherlands, 2008, ISBN 978-3-87155-979-2, pp.1497-1502

[11] Houdková, Š., Bláhová, O., Tichotová, P., Novotná, K., Tribological characteristics of thermally sprayed coatings, In: Tribology of surface layers and coatings, proceeding of the 4th international tribology conference, (2004), June 17-18, Prague, Czech Republic, ISBN 80-2393123-7, pp. 1-8 
[12] Houdková, Š., Enžl, R., Bláhová, O., Abrasion wear rate evaluation of thermally sprayed coatings, Acta Metallurgica Slovaca, Vol. 10, no. 1(2004), pp. 792-794

[13] Bhushan, B., Introduction to Tribology, Pu. John Wiley \& Sons, NY, USA, (2002)

[14] Bolelli, G., Cannillo, V., Lusvarghi, L., Manfredini, T., Wear behaviour of thermally sprayed ceramic oxide coatings, Wear 261,(2006), pp.1298-1315

[15] Guilemany, J.M., Miguel, J.M., Vizcaino, S., Climent, F., Role of tree-body abrasion wear in the sliding wear behaviour of WC-Co coatings obtained by thermal spraying, Surface and coatings Technology 140 (2001) 141-146

[16] Berger, L.-M., Woydt, M., Zimmermann, S., Schwier, G., Enzl, R., Tribological behavior of HVOF-sprayed $\mathrm{Cr}_{2} \mathrm{C}_{3}-\mathrm{NiCr}$ and TiC-based coatings under high-temperature dry sliding, Conf. Proc. Int. Thermal Spray Conf. \& Exhibition ITSC 2004, 10-12 May, Osaka, Japan, (2004),CD (ISBN 3-87155-792-7), p.10

[17] Berger, L.-M. Zieris, R., Saaro, S., Oxidation of HVOF-sprayed hardmetal coatings, Conf. Proc. Int. Thermal Spray Conference \& Exhibition ITSC 2005, 2-4 May 2005, Basel, Switzerland, CD (ISBN 3-87155-793-5), pp. $969-976$ 